Sharif University of Technology
Scientia Iranica
Transactions E: Industrial Engineering
http://scientiairanica.sharif.edu

\title{
Designing a sustainable agile retail supply chain using multi-objective optimization methods (Case study: SAIPA Company)
}

\author{
E. Azizi ${ }^{a}$, H. Javanshir ${ }^{a, *}$, D. Jafari ${ }^{a, b}$, and S. Ebrahimnejad ${ }^{a, c}$ \\ a. Department of Industrial Engineering, South Tehran Branch, Islamic Azad University, Tehran, Iran. \\ b. Department of Industrial Engineering, Parand Branch, Islamic Azad University, Parand, Iran. \\ c. Departments of Industrial Engineering, Karaj Branch, Islamic Azad University, Karaj, Iran.
}

Received 11 April 2019; received in revised form 4 September 2019; accepted 23 September 2019

\section{KEYWORDS \\ Supply chain; \\ Agility; \\ Sustainability; \\ Multi-objective \\ optimization.}

\begin{abstract}
This paper aimed to design a sustainable agile retail supply chain using multi-objective optimization methods. To this end, a mathematical model was presented for the sustainable agile supply chain with five objectives, including "minimizing costs", "minimizing unanswered demand", "maximizing the quality of goods purchased from suppliers", "maximizing social responsibility or social benefits", and "minimizing environmental impacts". The NSGA-II, PESA, and SPEA-II algorithms were used to solve the proposed model, which was run in MATLAB software. After collecting data from the SAIPA Company's supply chain, the model was solved using the three algorithms. The results indicate that the SPEA-II algorithm produces more high quality responses, compared to the other two algorithms. Furthermore, it is found that the SPEA-II algorithm belongs to the Pareto front response. A decrease in environmental impacts did not affect on the problem responses due to the lack of a specific structure in the current system.
\end{abstract}

C) 2021 Sharif University of Technology. All rights reserved.

\section{Introduction}

At the beginning of the 21st century, the world was facing tremendous changes in all aspects, especially in the marketing and competition for technological innovation and customer needs. Mass markets, due to their customers increasing demands and expectations, sought to divide their markets. This led to major reforms in business priorities and the strategic perspectives adopted by organizations and enterprises. They found that agility is essential to their survival and competitiveness.

\footnotetext{
*. Corresponding author.

E-mail address: H_Javanshir@azad.ac.ir (H. Javanshir)
}

doi: 10.24200 /sci. 2019.53311 .3179
In addition, it was evident that no company had all the resources required to provide all opportunities in the market. To gain a competitive advantage in the global market, they thus need to be synchronized with suppliers and customers to integrate their operations and contribute to reaching an acceptable level of agility. This is generally referred to as an agile supply chain. Researches have identified flexibility, adaptability, and accountability as the main aspects of agile supply chains. According to [1], agility consists of two main factors: Responding to changes and turning them into opportunities. Therefore, agility is a response to a highly competitive and variable environment at the enterprise level. It follows the following four basic principles: enriching customers, controlling change and uncertainty, enhancing human resource capabilities, 
and participating in competition [1]. Considering that agility in an organization's supply chain directly affects the production of innovative products and their delivery to customers, it can be concluded that supply chain agility is critical to overall competitiveness [2].

Parallel advances in the fields of agility and supply chain management have introduced an agile supply chain. While agility is widely accepted as a winning strategy for growth, it is even considered as a basis for survival in some specific business environments; hence, the establishment of an agile supply chain is raised as a logical step for organizations [3]. According to the existing research literature, [4] developed a conceptual framework of an agile supply chain, in which many of the previous research findings were included [4]. In the framework presented in [4], customer satisfaction was investigated from four perspectives, including cost, time, performance, and stability and sustainability.

A series of conceptual approaches to supply chain agility has been developed, which include various references and modified models [4-10]. A summary of the previous research studies is shown in Table 1 [11-24].

A review of the previous works and an analysis of their methods and findings indicated that a large number of these articles have used questionnaires and presented no computational model. In some other studies in this field, the static conditions are assumed to improve the performance of the enterprises, and practically no inherent environmental uncertainty is concerned in each organization internal and external environment. Some traditional methods could provide relatively acceptable results under static conditions; otherwise, they would produce no reliable results. As already noted, agile retail supply chain modeling has not been examined concerning sustainability dimensions, and this is a research gap. To bridge this gap, this paper focused on the development of an agile retail supply chain using multi-objective optimization methods. In this regard, a multi-objective mathematical model for a sustainable agile supply chain was proposed, which was solved using metaheuristic algorithms.

\section{Mathematical modeling}

Supply chain development has always been one of the most important operational decisions in an organization, since the availability of an appropriate supply system, in addition to reducing system costs, accelerates the delivery and receipt of goods and thus leads to system improvement. This effect becomes more pronounced when location selection problems are solved with the organizations strategic problems simultaneously. The location selection for service facilities is one of the most important dimensions in an industrial society. Therefore, it seems advisable to examine the location selection of facilities and supply chain at the same time.

Considering supply chain problems, two factors (namely cost and agility or time to prepare an order) are of paramount importance. This becomes even more prominent when it comes to the supply chain for essentials. In continuation, the mathematical model of the problem is presented to design the supply chain problem properly in terms of integrity and agility.

The problem under study in this paper consists of four levels, including suppliers, producers, distributors, and sales centers with limited capacity, in which the location selection for facilities, distribution, and delivery of goods is addressed. To solve the real-world problems, some parameters of the model are considered fuzzy. The proposed model was developed based on previous studies $[25,26]$. The proposed model is novel in the following aspects:

- Considering the four levels of the supply chain, storehouse for facilities, location selection for facilities with limited capacity;

- Inventory considerations, taking sustainability dimensions into account, the company minimum flexibility level is predetermined, consideration of goals and constraints on flexibility and agility.

In summary, and in light of these points, the following assumptions were set for modeling:

- The model is multi-period and multi-product;

- The capacity of all facilities is limited;

- Customer demand is fuzzy;

- Retailers are attractive, and retailers with higher attractiveness have a priority to send the commodities;

- Distribution places and sales centers (customers) are potential;

- Transferring goods among retail centers is allowed. In other words, this study assumes that, concerning the requirements and conditions, a retailer can act as a distribution center and send goods to other retailers;

- The number of facilities is not predefined;

- All customer demands are met;

- The cost of maintenance depends upon the closing inventory and the deficiency is not allowed;

- The cost of transporting and transferring each product unit from the supply centers to the production centers is considered as the purchase price of raw materials;

- The cost of construction centers is considered fuzzy;

- The company minimum flexibility level is already predetermined. 
Table 1. Summary of previous research.

\begin{tabular}{|c|c|c|c|}
\hline Author(s) & Subject & Methodology & Findings \\
\hline Swafford et al. [2] & An investigation of supply chain agility & - & $\begin{array}{l}\text { Providing key agility } \\
\text { enhancement factors }\end{array}$ \\
\hline Gao et al. [11] & Smart decision support system & $\begin{array}{l}\text { Simon's } \\
\text { decision-making } \\
\text { process }\end{array}$ & System development \\
\hline Swafford et al. [12] & Supply chain agility & $\mathrm{CFA}^{\mathrm{a}}$ & $\begin{array}{l}\text { Creating integrity and } \\
\text { flexibility using IT }\end{array}$ \\
\hline Gosling et al. [14] & $\begin{array}{l}\text { Flexibility of the retail supply chain as } \\
\text { a determinant of supplier selection }\end{array}$ & - & $\begin{array}{l}\text { Investigating the } \\
\text { relationship between } \\
\text { flexibility and supplier }\end{array}$ \\
\hline Ngai et al. [15] & $\begin{array}{l}\text { An investigation of IT, operational and } \\
\text { management competencies for supply } \\
\text { chain agility }\end{array}$ & - & $\begin{array}{l}\text { Investigating factors } \\
\text { affecting the supply } \\
\text { chain suitability }\end{array}$ \\
\hline Moon et al. [16] & Supply chain flexibility measurement & $\mathrm{SCF}$ & $\begin{array}{l}\text { An overview of } \\
\text { various SCFs }\end{array}$ \\
\hline Yusuf et al. [17] & $\begin{array}{l}\text { Diffusion of agility and cluster } \\
\text { competition in oil and gas supply } \\
\text { chains }\end{array}$ & - & $\begin{array}{l}\text { Increasing cluster and } \\
\text { more active levels } \\
\text { of agile practices }\end{array}$ \\
\hline Gligor et al. [18] & Supply chain agility performance & Financial Ratios & $\begin{array}{l}\text { Agility contributes to } \\
\text { cost efficiency and } \\
\text { customer effectiveness. }\end{array}$ \\
\hline Wu et al. [20] & $\begin{array}{l}\text { Examining a competitive advantage } \\
\text { through the retail supply chain } \\
\text { agility under uncertainty conditions }\end{array}$ & $\begin{array}{l}\text { Closed loop analysis } \\
\text { network process, } \\
\text { fuzzy decision making }\end{array}$ & $\begin{array}{l}\text { Integrating process, } \\
\text { information and strategic } \\
\text { alliance for competitive } \\
\text { advantage and innovation }\end{array}$ \\
\hline Chan et al. [21] & $\begin{array}{l}\text { The study of the effects of strategic } \\
\text { flexibility, manufacturing, production, } \\
\text { and the retail supply chain agility on } \\
\text { the company's performance }\end{array}$ & $\begin{array}{l}\text { Structural equation } \\
\text { modeling }\end{array}$ & $\begin{array}{l}\text { Developing a conceptual } \\
\text { framework and confirming } \\
\text { the effect of structural } \\
\text { and strategic flexibility } \\
\text { on agility }\end{array}$ \\
\hline Han et al. [22] & $\begin{array}{l}\text { IT flexibility for supply } \\
\text { chain management }\end{array}$ & 一 & $\begin{array}{l}\text { Presenting a research } \\
\text { model through combining } \\
\text { operational, functional and } \\
\text { strategic IT flexibilities }\end{array}$ \\
\hline Battistella et al. [24] & $\begin{array}{l}\text { Providing business agility through } \\
\text { focused capabilities }\end{array}$ & - & $\begin{array}{l}\text { Providing three macro } \\
\text { features to reconfigure } \\
\text { the business model }\end{array}$ \\
\hline Ocampo et al. [25] & $\begin{array}{l}\text { Providing a method to estimate the } \\
\text { effect of advanced manufacturing } \\
\text { tools on manufacturing competition } \\
\text { in clothing industry }\end{array}$ & $\begin{array}{l}\text { Hybrid three-phased } \\
\text { qualitative and } \\
\text { quantitative method } \\
\text { and AMTs }\end{array}$ & $\begin{array}{l}\text { Cost, flexibility, delivery } \\
\text { time and environmental } \\
\text { protection are the main } \\
\text { factors affecting the } \\
\text { manufacturing competition } \\
\text { in the clothing industry in } \\
\text { Central America. }\end{array}$ \\
\hline
\end{tabular}

${ }^{a}$ CFA: Confirmatory Factor Analysis 


\subsection{Model indices and parameters}

I Includes points with coordinates $\left(c_{i}, d_{i}\right)$ and actual point sets for supply centers $(i=1,2, \cdots, I)$

$J \quad$ Includes points with coordinates $\left(a_{j}, b_{j}\right)$ and actual point sets for production centers $(j=1,2, \cdots, J)$

$K \quad$ Contains points with coordinates $\left(x_{k}, y_{k}\right)$ and the potential point sets for distribution centers $(k=1,2, \cdots, K)$

$L \quad$ Includes points with coordinates $\left(x_{l}^{\prime}, y^{\prime}\right)$ and potential point sets for the retail centers $(l=1,2, \cdots, L)$

$S \quad$ Set of products $(s=1,2, \cdots, S)$

$V \quad$ Set of vehicles

$T \quad$ Set of programing periods $(t=$ $1,2, \cdots, T)$

The model parameters are listed below:

$\tilde{d}_{l t}^{s} \quad$ Demand for product $s$ by retailer $l$ during period $t$

$\tilde{f}_{k} \quad$ Cost of establishing a distribution center at location $k$

$\tilde{f}_{l} \quad$ Cost of establishing a retail center at location $l$

$B 0 l \quad$ Maximum attractiveness of $i$ th customer

$B 1 \quad$ Attractiveness index of $i$ th customer

$B_{l} \quad=B 0_{l} e^{-\gamma d^{2}}+\alpha$, where $d$ is Euclidean distance and $\lambda$ is attractiveness index

$d_{i j} \quad$ Distance between $i$ th supplier and $j$ th producer, calculated as Euclidean distance

$d_{j k} \quad$ Distance between $j$ th producer and $k$ th distributor, calculated as Euclidean distance

$d j_{j} \quad$ Distance between $j$ th producer and his storehouse, calculated as Euclidean distance

$d j_{j k} \quad$ Distance between $j$ th producer and $k$ th distributor, calculated as Euclidean distance

$d_{k l} \quad$ Distance between $k$ th distributor and $i$ th retailer, calculated as Euclidean distance

$d k_{k} \quad$ Distance between the storehouse of distributor $k$ th and $i$ th retailer, calculated as Euclidean distance

$d k_{k l} \quad$ Distance between $i$ th retailer and retailer i', calculated as Euclidean distance

$c_{i j}^{s} \quad$ All transportation and displacement costs for product $s$ from supply center $i$ to production center $j$ $c q_{j j}^{s} \quad$ All transportation and displacement costs for product $s$ from production center $j$ to its storehouse

$c q_{k k}^{s} \quad$ All transportation and displacement costs for product $s$ from the distribution center $k$ to its storehouse

$c_{j k}^{s} \quad$ All transportation and displacement costs for product $s$ from production center $j$ to distribution center $k$

$c q_{j k}^{s} \quad$ All transportation and displacement costs for product $s$ from the storehouse of production center $j$ to distribution center $k$

$c q_{k l}^{s} \quad$ All transportation and displacement costs for product $s$ from the storehouse of distribution center $k$ to retail center I

$c_{k l}^{s} \quad$ All transportation and displacement costs for product $s$ from distribution center $k$ to retail center $l$

$c_{l l^{\prime}}^{s} \quad$ All transportation and displacement costs for product $s$ from retail center $l$ to retail chain $l^{\prime}$

$c a_{i} \quad$ Delivery capacity of supply center at location $i$

$c a_{j} \quad$ Delivery capacity of production center at location $j$

$\mathrm{caj}_{j} \quad$ Capacity of production center's $s$ storehouse at location $j$

$c a_{k} \quad$ Delivery capacity of distributor center at location $k$

$c a k_{k} \quad$ Distribution center's storehouse capacity at location $k$

$\operatorname{cap}_{v} \quad$ Capacity of $v$ th vehicle

$h_{j}^{s} \quad$ Maintenance cost of each unit of product $s$ in production center's storehouse at location $j$

$h_{k}^{s} \quad$ Maintenance cost of each unit of product $s$ in distribution center's storehouse at location $k$

$L D C_{i s t} \quad$ Cost of delay for supplier $i$ in supplying product $s$ during period $t$

$O_{i s t} \quad$ Cost of ordering product $s$ to supplier $i$ during period $t$

F0 Flexibility considered by factory or organization

$F_{i s t} \quad$ Flexibility of supplier $i$ in supplying product $s$ during period $t$

$R_{\text {ist }} \quad$ Percentage of returned items s from supplier $i$ during period $t$

$R 0 \quad$ Maximum acceptable percentage for returned items during the programing horizon 


$\begin{array}{ll}\alpha_{l} & \begin{array}{l}\text { Number of job opportunities at } l \text { th } \\ \alpha_{k}\end{array} \\ & \text { sales center } \\ & \text { Number of job opportunities at } v \text { th } \\ & \text { distribution center } \\ & \text { The average waste generated at } j \text { th } \\ & \text { production center to produce each unit } \\ & \text { of product } s \\ & \text { The average hazardous substances used } \\ & \text { at } j \text { th production center to produce } \\ & \text { each unit of product } s \\ & \text { The average of missed working } \\ & \text { days resulting from damage at } j \text { th } \\ & \text { production center to produce each unit } \\ & \text { of product } s \\ & \text { Weight factor of produced waste } \\ & \text { (weight of the waste produced in the } \\ & \text { objective function) } \\ \theta_{w} & \text { Weight factor of hazardous substances } \\ & \text { (weight of hazardous substances in the } \\ & \text { objective function) } \\ \theta_{h} & \text { Damage weighting factor (damage } \\ & \text { weighting factor in the objective } \\ \text { function) } & \text { Weight of } i \text { th supplier } \\ \theta_{l} & \end{array}$

\subsection{Model variables}

The variables of the model are as follows:

$y_{l} \quad$ If the sales center is established at site 1 , its value is 1 ; otherwise, it is 0

$y_{k} \quad$ If the distribution center is established at site $k$, its value is 1 ; otherwise, it is 0

$x_{i j t}^{s v} \quad$ The product flow rate required by the product $s$ from the supply center $i$ to the production center $j$ during period $t$ by vehicle $v$

$x_{j k t}^{s v} \quad$ The product flow rate from the production center $j$ to the distribution center $k$ during period $t$ by vehicle $v$

$Q_{j j t}^{s v} \quad$ The flow rate of product $s$ from production center $j$ to its storehouse during period $t$ by vehicle $v$

$Q_{j k t}^{s v} \quad$ The product flow rate from the storehouse of producer $j$ to distribution center $k$ during period $t$ by vehicle $v$

$x_{k l t}^{s v} \quad$ The flow rate of product $s$ from distribution center $k$ to customer $l$ during period $t$ by vehicle $v$

$Q_{k k t}^{s v} \quad$ The product flow rate from the distributor $k$ to his storehouse during period $t$ by vehicle $v$

$Q_{k l t}^{s v} \quad$ The flow rate of product $s$ from storehouse of distribution center $k$ to customer $l$ during period $t$ by vehicle $v$ $x_{l l^{\prime} t}^{s v} \quad$ The flow rate of product $s$ from customer $l$ to customer $l^{\prime}$ during period $t$ by vehicle $v$

$U_{j t}^{s} \quad$ The remaining inventory of product $s$ in the storehouse of the production center $j$ during period $t$

$U_{k t}^{s} \quad$ The remaining inventory of product $s$ in the storehouse of the distributor center $k$ during period $t$

$z_{i j t}^{v} \quad$ If the vehicle $v$ moves from the supply center to the production center $j$ during period $t$, it is equal to 1 ; otherwise, it is 0

$z_{j k t}^{v} \quad$ If the vehicle $v$ moves from the production center $j$ to the distributor center $k$ during period $t$, it is equal to 1 ; otherwise, it is 0

$z_{k l t}^{v} \quad$ If the vehicle $v$ moves from the distributor center $k$ retail center $l$ during period $t$, it is equal to 1 ; otherwise, it is 0

$z_{j j t}^{v} \quad$ If the vehicle $v$ moves from the production center $j$ to its storehouse during period $t$, it is equal to 1 ; otherwise, it is 0

$z_{k k t}^{v} \quad$ If the vehicle $v$ moves from the distributor center $k$ to its storehouse during period $t$, it is equal to 1 ; otherwise, it is 0

$z j_{j k t}^{v} \quad$ If the vehicle $v$ moves from the storehouse of the producer $j$ to the distributor center $k$ during period $t$, it is equal to 1 ; otherwise, it is 0

$z k_{k l t}^{v} \quad$ If the vehicle $v$ moves from the storehouse of the distributor $k$ to retail center $l$ during period $t$, it is equal to 1 ; otherwise, it is 0

$z l_{l l^{\prime} t}^{v} \quad$ If the vehicle $v$ moves from the retail center $l$ to retail center $l^{\prime}$ during period $t$, it is equal to 1 ; otherwise, it is 0

$q_{l t}^{s} \quad$ The unanswered demand rate for product $s$ at retail center $l$ during period $t$

\subsection{The main structure of the model}

Using the above symbols, a hybrid fuzzy integer linear programming model is presented to develop a multiobjective integrated logistic as follows. This model involves both the objective function and constraints, which are described below.

The components of the first objective function are as follows: 
Facilities construction costs:

$$
\sum_{k \in K} \tilde{f}_{k} y_{k}+\sum_{j \in J} \tilde{f}_{j} y_{j}
$$

Transportation costs:

$$
\begin{aligned}
& \sum_{t \in T} \sum_{v \in V}\left(\sum_{s \in S} \sum_{i \in I} \sum_{j \in J} c_{i j}^{s} d_{i j} x_{i j t}^{s v}\right) \\
& \quad+\sum_{s \in S} \sum_{j \in J} \sum_{k \in K}\left(c_{j k}^{s} d_{j k} x_{j k t}^{s v}+c q_{j k}^{s} d j_{j k} Q_{j k t}^{s v}\right) \\
& \quad+\sum_{s \in S} \sum_{k \in K}\left(1-B_{l}\right) \sum_{l \in L}\left(c_{k l}^{s} d_{k l} x_{k l t}^{s v}\right. \\
& \left.\quad+c q_{k l}^{s} d k_{k l} Q_{k l t}^{s v}\right)+\sum_{s \in S} \sum_{j \in J} c q_{j j}^{s} d j_{j} Q_{j j t}^{s v} \\
& \left.\quad+\sum_{s \in S} \sum_{k \in K} c q_{k k}^{s} d k_{k} Q_{k k t}^{s t}\right) \\
& \quad+\sum_{s \in S} \sum_{l \in L} \sum_{l^{\prime} \in L} c q_{l l^{\prime}}^{s} d l_{l l^{\prime}} x_{l l^{\prime} t}^{s v} .
\end{aligned}
$$

Maintenance cost:

$$
\sum_{t \in T}\left(\sum_{s \in S} \sum_{j \in J} h_{j}^{s} U_{j t}^{s}+\sum_{s \in S} \sum_{k \in K} h_{k}^{s} U_{k t}^{s}\right) .
$$

Cost of ordering from supplier and cost of delay:

$$
\sum_{i \in I}\left(1-w_{i}\right) \sum_{t \in T} \sum_{j \in J} \sum_{s \in S}\left(o_{i s t}+L D C_{i s t}\right) \sum_{v \in V} x_{i j t}^{s v} .
$$

The cost components were described above separately and the first objective function of the model is derived from the sum of the above components. Thus the first objective function is presented as follows:

$$
\begin{aligned}
\min z 1= & \sum_{k \in K} f_{k} y_{k}+\sum_{j \in J} f_{i} y_{i} \\
& +\sum_{t \in T} \sum_{v \in V} \sum_{s \in S} \sum_{i \in I} \sum_{j \in J} c_{i j}^{s} d_{i j} x_{i j t}^{s v} \\
& +\sum_{s \in S} \sum_{j \in J} \sum_{k \in K}\left(c_{i k}^{s} d_{i k} x_{i k t}^{s v}+c_{i k}^{s} q_{i k} Q_{i k t}^{s v}\right) \\
& +\sum_{s \in S} \sum_{k \in K}\left(1-B_{l}\right) \sum_{l \in L}\left(c_{k l}^{s} d_{k l} x_{k l t}^{s v}\right. \\
& \left.+c q_{k l}^{s} d k_{k l} Q_{k l t}^{s v}\right)+\sum_{s \in S} \sum_{j \in J} c q_{j j}^{s} d j_{j} Q_{j j t}^{s v} \\
& \left.+\sum_{s \in S} \sum_{k \in K} c q_{k k}^{s} d k_{k} Q_{k k t}^{s}\right)
\end{aligned}
$$

$$
\begin{aligned}
& +\sum_{s \in S} \sum_{l \in L} \sum_{l^{\prime} \in L} c_{l l^{\prime}}^{s} d l_{l l^{\prime}} x_{l l^{\prime} t}^{s v} \\
& +\sum_{t \in T}\left(\sum_{s \in S} \sum_{j \in J} h_{j}^{s} U_{j t}^{s}+\sum_{s \in S} \sum_{k \in K} h_{k}^{s} U_{k t}^{s}\right) \\
& +\sum_{i \in I}\left(1-w_{i}\right) \sum_{t \in T} \sum_{j \in J} \sum_{s \in S}\left(O_{i s t}+L D C_{i s t}\right) \\
& \sum_{v \in V} x_{i j t}^{s v} .
\end{aligned}
$$

The second objective function is that the goal is to minimize unanswered demand.

$$
\min z 2=\sum_{t} \sum_{l} \sum_{s} \frac{q_{l t}^{s}}{\tilde{d}_{l t}^{s}} .
$$

The third objective function of the model aims to maximize the quality of the goods purchased from suppliers:

$$
\max z 3 \sum_{i \in I} w_{i} \sum_{t \in T} \sum_{j \in J} \sum_{s \in S}\left(1-R_{i s t}\right) \sum_{v \in V} x_{i j t}^{s v} .
$$

The fourth objective function is that the goal is to maximize social responsibility or the social benefits, all of which are expressed as an average value (mean value), and weighted by their weight factors.

$$
\max z 4=\sum_{t \in T}\left(\sum_{k \in K} \alpha_{k} y_{k}+\sum_{k \in L} \alpha_{1} y_{l}\right) .
$$

The fifth objective function is reduction of environmental impact:

$$
\begin{aligned}
\min z 5= & \theta_{w} \sum_{t \in T} \sum_{j \in J} \sum_{s \in S} s p_{j s}\left(\sum_{v \in V} Q_{j j t}^{s v}+\sum_{k \in K} x_{j k t}^{s v}\right) \\
& +\theta_{h} \sum_{t \in T} \sum_{j \in J} \sum_{s \in S} s p_{j s}\left(\sum_{v \in V} Q_{j j t}^{s v}+\sum_{k \in K} x_{j k t}^{s v}\right) \\
& +\theta_{l} \sum_{t \in T} \sum_{j \in J} d l_{j} \sum_{s \in S}\left(\sum_{v \in V} Q_{j j t}^{s v}+\sum_{k \in K} x_{j k t}^{s v}\right)
\end{aligned}
$$

\section{Model constraints:}

Expression (10) calculates the unanswered demand rate:

$$
\begin{aligned}
& \sum_{v}\left(\sum_{k}\left(x_{k l t}^{s v}+Q_{k l t}^{s v}\right)+\sum_{l^{\prime} \in L} x_{l l^{\prime} t}^{s v}\right)+q_{l t}^{s}=\tilde{d}_{l t}^{s} \\
& \quad \forall l, t, s .
\end{aligned}
$$

Expressions (11) to (16) are associated with the constraints of the product flow in the nodes: 


$$
\begin{array}{cl}
\sum_{v} \sum_{j}\left(x_{j k t}^{s v}+Q_{j k t}^{s v}\right)=\sum_{v}\left(\sum_{l} x_{k l t}^{s v}+Q_{k k t}^{s v}\right) \\
\forall k, s, t, \\
\sum_{v} \sum_{i} x_{i j t}^{s v}=\sum_{v}\left(\sum_{k} x_{j k t}^{s v}+Q_{j j t}^{s v}\right) \\
\forall j, s, t, \\
U_{j t}^{s}=\sum_{v} Q_{j j t}^{s v}+U_{j t-1}^{s}-\sum_{v} \sum_{k} Q_{j k t}^{s v} & \forall j, s, t, \\
U_{j 1}^{s}=\sum_{v} Q_{j j 1}^{s v}-\sum_{v} \sum_{k} Q_{j k 1}^{s v} & \forall j, s, \\
U_{k t}^{s}=\sum_{v} Q_{k k t}^{s v}+U_{k t-1}^{s}-\sum_{v} \sum_{k} Q_{k l t}^{s v} & \forall k, s, t, \\
U_{k 1}^{s}=\sum_{v} Q_{k k 1}^{s v}-\sum_{v} \sum_{k} Q_{k l 1}^{s v} & \forall k, s .
\end{array}
$$

Constraints (17) and (18) ensure that the output flow rate from producers and distributors storehouses is less than the sum of the input flow into their storehouses:

$$
\begin{array}{ll}
\sum_{v} \sum_{k} Q_{j k t}^{s v} \leq \sum_{v} Q_{j j t}^{s v} \quad & \forall j, s, t, \\
\sum_{v} \sum_{l} Q_{k l t}^{s v} \leq \sum_{v} Q_{k k t}^{s v} & \forall k, s, t .
\end{array}
$$

Expressions (19) to (23) guarantee that the flow is only between the points where a facility is constructed and between the places where the total flow in each facility does not exceed its capacity:

$$
\begin{array}{ll}
\sum_{v} \sum_{s} \sum_{j} x_{i j t}^{s v} \leq c a_{i} & \forall i, t, \\
\sum_{v}\left(\sum_{s} \sum_{k} x_{j k t}^{s v}+\sum_{s} Q_{j j t}^{s v}\right) \leq c a_{j} & \forall j, t, \\
\sum_{v}\left(\sum_{s} \sum_{l} x_{k l t}^{s v}+\sum_{s} Q_{k k t}^{s v}\right) \leq c a_{k} y_{k} & \forall k, t, \\
\sum_{s} U_{j t}^{s} \leq c a j_{j} & \forall j, t, \\
\sum_{s} U_{k t}^{s} \leq c a k_{k} y_{k} & \forall k, t .
\end{array}
$$

Expressions (24) and (25) ensure that at least one of the potential centers is active:

$$
\sum_{k} y_{k} \geq 1
$$

$$
\sum_{l} y_{l} \geq 1
$$

Expressions (26) to (28) show that vehicles arriving at the centers and storehouses have left the sites:

$$
\begin{array}{ll}
\sum_{v} \sum_{i} z_{i j t}^{v}=\sum_{v} z_{j j t}^{v}+\sum_{v} \sum_{k} z_{j k t}^{v} \quad \forall j, t, \\
\sum_{v} \sum_{j}\left(z_{j k t}^{v}+z j_{j k t}^{v}\right)=\sum_{v} \sum_{l} z_{k l t}^{v}+\sum_{v} z_{k k t}^{v} \\
\sum_{v} z_{j j t}^{v}=\sum_{v} \sum_{k} z j_{j k t}^{v} & \forall j, t
\end{array}
$$

Expressions (29)-(31) ensure that distribution centers, markets, and customers are met by at least one vehicle:

$$
\begin{array}{ll}
\sum_{v} \sum_{i} z_{i j t}^{v} \geq 1 & \forall j, t, \\
\sum_{v} \sum_{j}\left(z_{j k t}^{v}+z j_{j k t}^{v}\right) \geq 1 & \forall k, t, \\
\sum_{v} \sum_{k}\left(z_{k l t}^{v}+z k_{k l t}^{v}\right) \geq 1 & \forall l, t .
\end{array}
$$

Expressions (32) to (39) guarantee that the goods are transported by a vehicle from one center to another only if the concerned vehicle has been driven between the concerned sites:

$$
\begin{array}{ll}
x_{i j t}^{s v} \leq M \times z_{i j t}^{v} & \forall i, j, t, s, v, \\
x_{j k t}^{s v} \leq M \times z_{j k t}^{v} & \forall k, j, t, s, v, \\
x_{k l t}^{s v} \leq M \times z_{k l t}^{v} & \forall k, l, t, s, v, \\
Q_{j j t}^{s v} \leq M \times z_{j j t}^{v} & \forall j, t, s, v, \\
Q_{k k t}^{s v} \leq M \times z_{k k t}^{v} & \forall k, t, s, v, \\
Q_{j k t}^{s v} \leq M \times z j_{j k t}^{v} & \forall k, j, t, s, v, \\
Q_{k l t}^{s v} \leq M \times z k_{k l t}^{v} & \forall k, l, t, s, v, \\
x_{l l^{\prime} t}^{s v} \leq M \times z l_{l l^{\prime} t}^{v} & \forall i, j, t, s, v .
\end{array}
$$

Constraint (40) ensures that the total returned items do not exceed the maximum allowable level:

$$
\sum_{t \in T} \sum_{i \in I} R_{i s t} \sum_{v \in V} \sum_{i \in I} x_{i j t}^{s v} \leq R_{0} \sum_{t \in T} \sum_{l \in L} \tilde{d}_{l s}^{t} \quad \forall s .
$$

Constraint (41) refers to the supplier flexibility level, which should be higher than the level determined by the organization or factory: 


$$
F_{i s t} \sum_{v \in V} \sum_{j \in J} x_{i j t}^{s v} \geq F_{0} \quad \forall i, s, t .
$$

Constraints (42) and (43) are also logical and obvious limitations on problem decision variables:

$$
\begin{aligned}
& y_{l}, y_{k} \in\{0,1\} \quad \forall l, k, \\
& x_{i j t}^{s v}, x_{i k t}^{s v}, Q_{i j t}^{s v}, Q_{i k t}^{s v}, x_{k l t}^{s v}, Q_{k k t}^{s v}, Q_{k l t}^{s v}, U_{j t}^{s}, U_{k t}^{s} \geq 0 \\
& \forall i, j, k, l, s, t .
\end{aligned}
$$

As can be observed, the proposed model has four objectives along with fuzzy parameters. The fuzzy model is transformed into an equivalent deterministic model based on the Jiminez ranking method (see [2730]).

The first deterministic objective function after defuzzification:

$$
\begin{aligned}
& \min z 1=\sum_{k \in K} \frac{f_{k}^{1}+2 f_{k}^{2}+f_{k}^{3}}{4} y_{k} \\
& +\sum_{l \in L} \frac{f_{l}^{1}+2 f_{l}^{2}+f_{l}^{3}}{4} y_{l} \\
& +\sum_{t \in T} \sum_{v \in V}\left(\sum_{s \in S} \sum_{i \in I} \sum_{j \in J} c_{i j}^{s} d_{i j} x_{i j t}^{s v}\right. \\
& +\sum_{s \in S} \sum_{j \in J} \sum_{k \in K}\left(c_{j k}^{s} d_{j k} x_{j k t}^{s v}+c q_{j k}^{s} d j_{j k} Q_{j k t}^{s v}\right) \\
& +\sum_{s \in S} \sum_{k \in K}\left(1-B_{l}\right) \sum_{l \in L}\left(c_{k l}^{s} d_{k l} x_{k l t}^{s v}\right. \\
& \left.+c q_{k l}^{s} d k_{k l} Q_{k l t}^{s v}\right)+\sum_{s \in S} \sum_{j \in J} c q_{j j}^{s} d j_{j} Q_{j j t}^{s v} \\
& \left.+\sum_{s \in S} \sum_{k \in K} c q_{k k}^{s} d k_{k} Q_{k k t}^{s}\right) \\
& +\sum_{s \in S} \sum_{l \in L} \sum_{l^{\prime} \in L} c_{l l^{\prime}}^{s} d l_{l l^{\prime}} x_{l l^{\prime} t}^{s v} \\
& +\sum_{t \in T}\left(\sum_{s \in S} \sum_{j \in J} h_{j}^{s} U_{j t}^{s}+\sum_{s \in S} \sum_{k \in K} h_{k}^{s} U_{k t}^{s}\right) \\
& +\sum_{i \in I} \min z 2 \\
& =\sum_{t} \sum_{l} \sum_{s} \frac{q_{l t}^{s}}{\frac{d_{l t}^{s 1}+2 d_{l t}^{s 2}+d_{l t}^{s 3}}{4}}\left(1-w_{i}\right) \\
& \sum_{t \in T} \sum_{j \in J} \sum_{s \in S}+\left(O_{i s t}+L D C_{i s t}\right) \sum_{v \in V} x_{i j t}^{s v} \text {. }
\end{aligned}
$$

The second deterministic objective function:

$$
\min z 2=\sum_{t} \sum_{l} \sum_{s} \frac{q_{l t}^{s}}{\frac{d_{l t}^{s 1}+2 d_{l t}^{s 2}+d_{l t}^{s 3}}{4}} .
$$

The deterministic constraints:

$$
\begin{aligned}
& \sum_{v}\left(\sum_{k}\left(x_{k l t}^{s v}+Q_{k l t}^{s v}\right)+\sum_{l^{\prime} \in L} x_{l l^{\prime} t}^{s v}\right)+q_{l t}^{s} \\
&=\alpha \frac{d_{l t}^{s 1}+d_{l t}^{s 2}}{2}+(1-\alpha) \frac{d_{l t}^{s 2}+d_{l t}^{s 3}}{2} \quad \forall l, t, s, \quad \\
& \sum_{t \in T} \sum_{i \in I} R_{i s t} \sum_{v \in V} \sum_{i \in I} x_{i j t}^{s v} \leq R_{0} \sum_{t \in T} \sum_{l \in L}\left[\alpha \frac{d_{l t}^{s 1}+d_{l t}^{s 2}}{2}\right. \\
&\left.+(1-\alpha) \frac{d_{l t}^{s 2}+d_{l t}^{s 3}}{2}\right] \\
& \forall s .
\end{aligned}
$$

\section{Problem solving method}

Regarding the existence of the strategic and operational aspects of this programming problem, the response time and quality were opposite. Therefore, it is necessary to strike a balance between the minimum time and response quality. In this paper, the NSGA-II, PESA, and SPEA-II algorithms were used to solve the proposed model. Here an overview of these algorithms is presented.

\subsection{NSGA-II algorithm}

The NSGAII algorithm is one of the most commonly used and most powerful algorithms for solving multiobjective optimization problems, and it has been proven to be effective in solving various problems. To solve the shortcomings of the first version of the biobjective genetic algorithm, Deb et al. [33] developed the second version. In this modified version, in addition to the quality of the responses, the diversity of Pareto optimal responses is also taken into account. In this algorithm, two main criteria are considered for responses: First, they select high quality responses, and if there are two identical high-quality responses, the one with greater sorting is considered. Therefore, we must first solve the quality problem, and then evaluate the ranking. The NSGA-II algorithm has two known phases: The first phase uses the ranking criteria and the concept dominance, and the second phase, which is related to their sorting, uses the congestion distance. In the first phase, the responses are sorted and the following values are calculated: The number of times a response is dominated and the set of responses dominated by the current response. To estimate the two values above, all the responses should be compared. If some responses are not dominant, they are nondominant and approximate of Pareto front [27]. 


\subsection{SPEA and SPEA-II algorithms}

Both SPEA and SPEAII algorithms are efficient algorithms, using an external archive to store the nondominant responses, which can be found throughout the algorithm search. In the SPEA algorithm, there were weaknesses in calculating positives and fitness. There was also no secondary criterion to compare the non-dominant responses. Thus, Zitzler et al. [34] developed the second version of the algorithm after addressing the weaknesses. The SPEAII algorithm acts as follows: Creating an initial population, calculating the fitness of each response (i.e., the sum of raw fitness and density of each response), placing non-dominant responses in a set through applying the problem conditions, selecting the parent based on pairing competition method, adopting mutation and combination operators to have offspring [28].

One of the most popular multi-objective algorithms is the second version of the Pareto envelopebased selection algorithm, in which genetic operators are used to generating new responses. The early version of this algorithm had some selection shortcomings. Hence, the modified version of this algorithm was presented by Montazeri-Gh and Mahmoodi-K [29]. The algorithm works as follows: Generating the first population and emptying the external archive, dividing the space into a certain number of super-cubes containing the objective functions, archiving the non-dominant responses according to the process, and selecting the parent to perform the combination and the mutation.

\section{Computational results}

In this section, to solve the proposed model by the three algorithms, the required data on the model parameters were collected from SAIPA Company and the model was solved accordingly. Regarding the collected information, the company supply chain includes 18 suppliers, 361 producers, 587 distributors, 467 retailers, 20 products, and 12 programming periods. Due to a large number of centers in this supply chain, multivariate decision-making methods were used to rank the centers at different levels of the supply chain. Consequently, the centers were selected to solve the model. After weighting the sites, the model was solved using the above mentioned algorithms in the MATLAB software and the results were analyzed.

\subsection{Weighting}

In the present study, two fuzzy AHP and fuzzy TOPSIS methods were used to weigh the suppliers. To this end, the assessment criteria were first determined, and then the fuzzy AHP method was used to weigh them. Finally, the fuzzy TOPSIS method was used to weigh the sites.

First, the factors affecting the location-allocation were determined based on the comments received from some selected experts. Lawshe's validation method was employed to determine the validity of the criteria. In a similar vein, the comments obtained from 20 experts were used to determine the validity of the points; the results are shown in Table 2.

Table 2. Factors affecting location selection.

\begin{tabular}{lcccc}
\hline \multicolumn{1}{c}{ Factors } & $\begin{array}{c}\text { Total number } \\
\text { of assessors }\end{array}$ & $\begin{array}{c}\text { Number of assessors } \\
\text { accepting the item }\end{array}$ & $\begin{array}{c}\text { CVR } \\
\text { ITEM }\end{array}$ & $\begin{array}{c}\text { Accepted } \\
\text { CVR }\end{array}$ \\
\hline Provision of relevant information & 20 & 15 & 0.5 & 0.5 \\
Response time to needs & 20 & 16 & 0.6 & 0.5 \\
Return to buyback time & 20 & 16 & 0.6 & 0.5 \\
Quality of transportation & 20 & 17 & 0.7 & 0.5 \\
Different transportation modes & 20 & 17 & 0.7 & 0.5 \\
Remote communication & 20 & 18 & 0.8 & 0.5 \\
Cost of land & 20 & 19 & 0.9 & 0.5 \\
Cost of transportation & 20 & 18 & 0.8 & 0.5 \\
Cost of labor & 20 & 12 & 0.2 & 0.5 \\
Cost of freight & 20 & 17 & 0.7 & 0.5 \\
Availability of land & 20 & 15 & 0.5 & 0.5 \\
Climate & 20 & 12 & 0.2 & 0.5 \\
Proximity to construction unit & 20 & 16 & 0.5 & 0.5 \\
Location quality and reliability & 20 & 16 & 0.6 & 0.5 \\
Skilled labor force & 20 & 13 & 0.3 & 0.5 \\
Availability of labor force & 20 & 14 & 0.14 & 0.5 \\
\hline
\end{tabular}


Table 3. Weight of the main and secondary factors affecting the location selection.

\begin{tabular}{|c|c|c|c|c|}
\hline Sub-criteria & $\begin{array}{c}\text { Sub criteria's } \\
\text { weight }\end{array}$ & Criteria & $\begin{array}{c}\text { Criteria's } \\
\text { weight }\end{array}$ & $\begin{array}{c}\text { Factor's } \\
\text { weight }\end{array}$ \\
\hline Proximity to construction unit & 0.30 & \multirow{3}{*}{ Location } & \multirow{3}{*}{0.29} & 0.087 \\
\hline Availability of land & 0.43 & & & 0.124 \\
\hline Availability and quality of location & 0.27 & & & 0.078 \\
\hline Cost of land & 0.46 & \multirow{3}{*}{ Cost } & \multirow{3}{*}{0.31} & 0.142 \\
\hline Cost of transportation & 0.27 & & & 0.083 \\
\hline Cost of freight & 0.27 & & & 0.083 \\
\hline Return to buyback time & 0.35 & \multirow{3}{*}{ Accountability } & \multirow{3}{*}{0.21} & 0.073 \\
\hline Response time to needs & 0.35 & & & 0.073 \\
\hline Provision of relevant information & 0.30 & & & 0.063 \\
\hline Quality of transportation & 0.44 & \multirow{3}{*}{ Transportation } & \multirow{3}{*}{0.20} & 0.088 \\
\hline Remote communication & 0.15 & & & 0.30 \\
\hline Different transportation modes & 0.41 & & & 0.082 \\
\hline
\end{tabular}

It should be noted that the validity of some criteria has not yet been confirmed, and the final criteria include the following: provision of relevant information, response time to needs, return to buyback time, quality of transportation, different transportation modes, distance communication, cost of land, cost transportation, cost of freight, availability of land, proximity to the construction site, and location quality and reliability [30,31].

The confirmed criteria were categorized into four main categories (namely "cost", "location", "accountability", and "transportation") as major factors. After determining the main factors and secondary factors, the fuzzy AHP method was used to weigh them (see Table 3).

Then, the Fuzzy TOPSIS ranking method was run to rank the four concerned locations. To this end, the following steps were taken respectively:

1. A questionnaire was used to collect comments and then the table of concerned criteria was formed by averaging the comments;

2. Then the matrix normalization step was carried out, and a table of standard criteria is formed on this basis;

3. The matrix was then weighted.

Finally, each location was ranked by determining the ideal and anti-ideal options and estimating the closeness coefficient. According to the weight allocated to the SAIPA Company various supply chain levels and from the facilities of higher priority, 10 suppliers, 50 producers, 50 distributors, and 100 retailers were selected and the problem was solved using the three NSGA-II, PESA, and SPEA-II algorithms.

\subsection{Solving the model}

As, mentioned above, the SAIPA Company supply chain data was used to solve the model using the algorithms. Three algorithms were used to solve the model based on the above parameters, and the results of the three algorithms were compared based on the following comparative indices.

\subsubsection{Comparative indices}

There are numerous different indices to evaluate the quality and dispersion of multi-objective metaheuristic algorithms. In this paper, the three indices of quality, uniformity, and dispersion [31] were considered in comparisons.

Quality Index (QM): This index is used to compare the quality of the Pareto responses obtained by each method [32]. It ranks all Pareto responses obtained by each of the three algorithms and determines what percentage of the first-level responses belongs to each method. The greater the percentage is, the higher the algorithm quality will be.

Uniformity Index (SM): This measure tests the uniformity of the distribution of Pareto responses obtained at the response boundary. This index is defined as follows:

$$
\frac{\sum_{i=1}^{N-1}\left|d_{\text {mean }}-d_{i}\right|}{(N-1) \times d_{\text {mean }}}
$$

In the above equation, $d_{i}$ is the Euclidean distance 
between the two adjacent non-dominant responses and $d_{\text {mean }}$ represents the mean values of $d_{i}$.

Dispersion Index (DM): This index is used to determine the non-dominant responses on the optimal boundary. The index is defined as follows:

$$
D=\sqrt{\sum_{i=1}^{N} \max \left(\left\|x_{t}^{i}-y_{t}^{i}\right\|\right)} .
$$

In this equation, $\left\|x_{t}^{i}-y_{t}^{i}\right\|$ shows the Euclidean distance between the two adjacent responses $x_{t}^{i}$ and $y_{t}^{i}$ on the optimal boundary.

In addition to the described indices, the number of Pareto responses and runtime indices are also considered as follows:

Number of Pareto Responses (DNS): This index contains the number of output responses for each algorithm.

Runtime (Time): This index shows the runtime of each repetition for the algorithms in seconds.

\subsubsection{Sample problems}

In the previous step, the location of the facilities was weighted. To solve the model, some problems as the SAIPA Company's sub-problems were developed and the facilities of a higher priority were selected. Then, three NSGA-II, PESA, and SPEA-II algorithms were used to solve the selected sample problems.

\subsubsection{Model solving results}

In this section, the experimental problems were solved using the three proposed algorithms and the results were analyzed. According to the comparison index, the results of the three algorithms are shown in Table 4.

It should be noted that $I / J / K / L$ stands for the number of supply centers $(I)$, the number of production centers $(J)$, the number of distribution centers $(K)$, and the number of retail centers $(L)$. In all problems, the number of products, periods, and vehicles were considered 3,12 , and 40 , respectively (Table 4, Figures 1-4).

As shown in Table 4 and Figure 1, in all cases, the response quality generated by the SPEA-II algorithm was higher than the other two NSGA-II and PESA algorithms. Between the other two algorithms, the NSGA-II had a higher potential to achieve Pareto's responses.

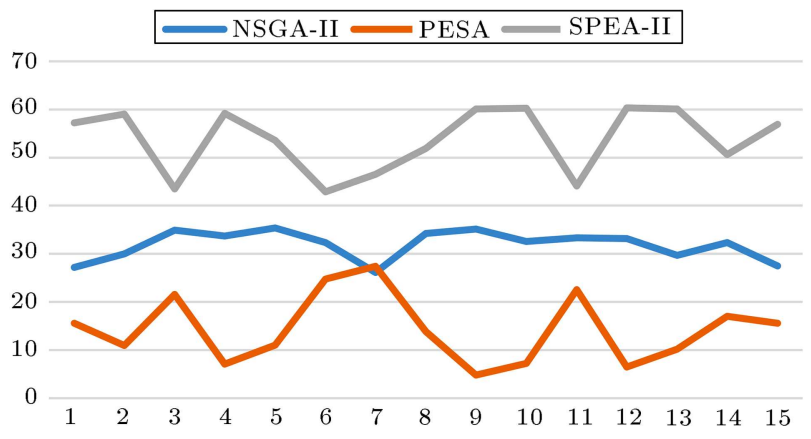

Figure 1. QM comparison for the three algorithms.

Table 4. Comparison of results for the three NSGA-II, PESA and SPEA-II algorithms.

\begin{tabular}{|c|c|c|c|c|c|c|c|c|c|c|c|c|c|c|c|}
\hline \multirow[b]{2}{*}{$\begin{array}{c}\text { Problem } \\
\text { size } \\
\text { (node) }\end{array}$} & \multicolumn{5}{|c|}{ NSGA-II } & \multicolumn{5}{|c|}{ PESA } & \multicolumn{5}{|c|}{ SPEAII } \\
\hline & $\sum_{\sigma}$ & $\sum_{\mathscr{\Omega}}$ & $\sum_{A}^{\prime}$ & $\sum_{\text {且 }}$ & $\begin{array}{l}\mathscr{D} \\
\text { Z } \\
\text { A }\end{array}$ & $\sum_{\sigma}$ & $\sum_{n=1}$ & 公 & 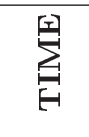 & $\begin{array}{l}\boldsymbol{N} \\
Z \\
\end{array}$ & $\sum_{\sigma}$ & $\sum_{\infty}$ & $\stackrel{\sum_{A}}{A}$ & $\sum_{\text {国 }}$ & 兄 \\
\hline $10 / 10 / 20 / 20$ & 27.2 & 0.75 & 2117.5 & 179.2 & 80 & 15.6 & 0.7 & 1131.9 & 81.3 & 29 & 57.2 & 0.89 & 3584.6 & 155.2 & 61 \\
\hline $10 / 10 / 20 / 40$ & 29.99 & 0.72 & 2146.9 & 235.9 & 99 & 10.98 & 0.47 & 1175.6 & 90.6 & 24 & 59.04 & 0.97 & 3595.3 & 259.2 & 85 \\
\hline $10 / 10 / 20 / 60$ & 34.93 & 1.67 & 2177.6 & 254.4 & 53 & 21.61 & 0.56 & 1236.8 & 97.8 & 42 & 43.46 & 1.98 & 3689.5 & 269.1 & 98 \\
\hline $10 / 10 / 20 / 80$ & 33.69 & 0.73 & 2298.5 & 286.5 & 67 & 7.12 & 0.71 & 1289.1 & 111.9 & 19 & 59.19 & 0.78 & 3700.3 & 282.5 & 92 \\
\hline $10 / 10 / 20 / 100$ & 35.36 & 0.71 & 2505.4 & 297.7 & 98 & 11.07 & 0.44 & 1353.4 & 173.4 & 30 & 53.57 & 0.92 & 3701.1 & 363.1 & 81 \\
\hline $10 / 30 / 50 / 20$ & 32.33 & 0.87 & 2566.9 & 309.4 & 31 & 24.8 & 0.78 & 1458.6 & 273.6 & 79 & 42.87 & 1.51 & 3703.5 & 471.8 & 89 \\
\hline $10 / 30 / 50 / 40$ & 26.13 & 0.64 & 2652.4 & 337.9 & 87 & 27.38 & 0.47 & 1502.8 & 280.1 & 47 & 46.49 & 1.17 & 3951.9 & 481.8 & 90 \\
\hline $10 / 30 / 50 / 60$ & 34.26 & 0.85 & 2820.3 & 363.4 & 45 & 13.88 & 0.62 & 1511.4 & 289.2 & 31 & 51.86 & 1.06 & 3993.2 & 512.4 & 88 \\
\hline $10 / 30 / 50 / 80$ & 35.11 & 0.68 & 2834.7 & 370.2 & 88 & 4.82 & 0.49 & 1598.3 & 306.2 & 38 & 60.07 & 1.04 & 4145.1 & 584.7 & 99 \\
\hline $10 / 30 / 50 / 100$ & 32.56 & 0.75 & 2925.8 & 379.2 & 50 & 7.22 & 0.7 & 1659.3 & 315.7 & 21 & 60.22 & 0.91 & 4197.3 & 595.2 & 51 \\
\hline $10 / 50 / 50 / 20$ & 33.35 & 0.98 & 2933.4 & 404.5 & 31 & 22.58 & 0.74 & 1668.1 & 322.6 & 49 & 44.07 & 1.19 & 4260.3 & 659.2 & 47 \\
\hline $10 / 50 / 50 / 40$ & 33.20 & 0.73 & 2977.2 & 449.6 & 42 & 6.47 & 0.64 & 1692.7 & 324.5 & 48 & 60.33 & 1.34 & 4286.7 & 646.0 & 53 \\
\hline $10 / 50 / 50 / 60$ & 29.69 & 0.99 & 2977.5 & 496.2 & 30 & 10.24 & 0.76 & 1722.4 & 354.9 & 51 & 60.06 & 1.01 & 4336.9 & 767.2 & 95 \\
\hline $10 / 50 / 50 / 80$ & 32.32 & 0.96 & 2984.9 & 515.8 & 56 & 17.05 & 0.65 & 1767.7 & 396.2 & 64 & 50.63 & 0.97 & 4375.3 & 790.6 & 72 \\
\hline $10 / 50 / 50 / 100$ & 27.48 & 0.78 & 2990.6 & 571.4 & 70 & 15.59 & 0.70 & 1972.7 & 409.7 & 83 & 56.93 & 1.13 & 4405.3 & 835.7 & 109 \\
\hline
\end{tabular}




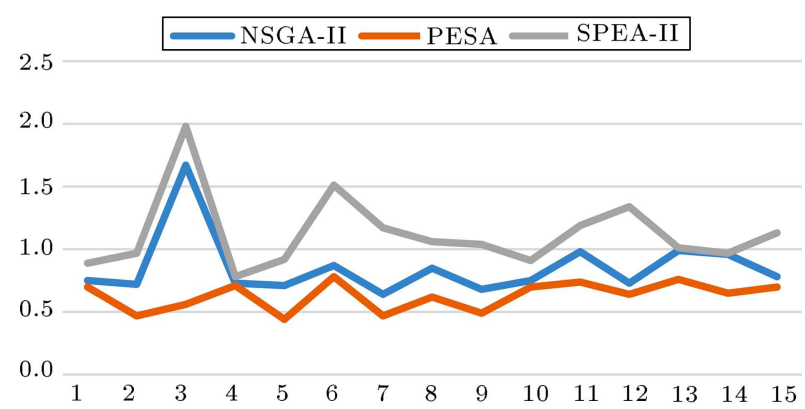

Figure 2. SM comparison for the three algorithms.

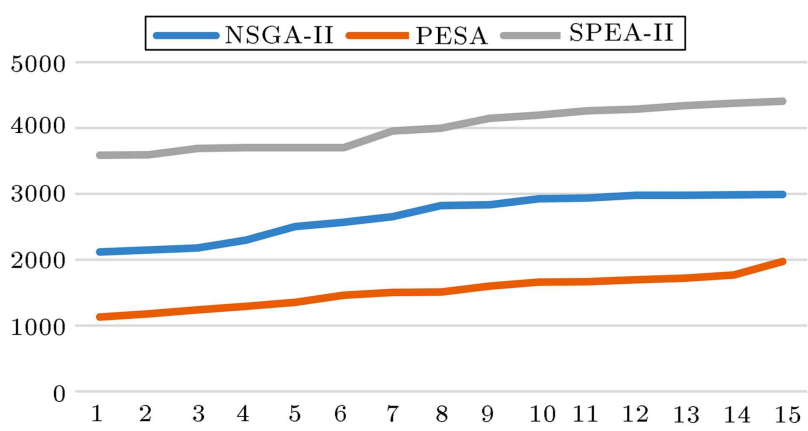

Figure 3. DM comparison for the three algorithms.

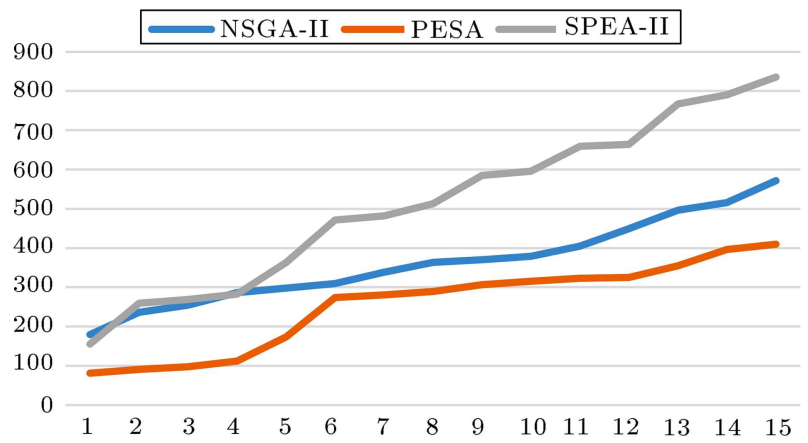

Figure 4. TIME comparison for the three algorithms.

Based on Table 4 and Figure 2, the best performance was found for the SPEA-II, NSGA-II, and PESA algorithms, respectively, with regard to the dispersion index. Furthermore, as shown in Table 4 and Figure 3, the PESA, NSGA-II, and SPEA-II, respectively, had better performance with regard to the uniformity index. According to the runtime index in Table 4 and Figure 4, PESA, NSGA-II, and SPEA-II had, respectively, the best performance.

Regarding the dispersion and uniformity indices, in all cases, the SPEA-II algorithm had a higher potential to search the response space and obtained the best and near-optimal solutions.

Since the SPEA-II algorithm had the best performance, in terms of quality, the Pareto front line produced by this algorithm was presented for problem $10 / 50 / 50 / 100$. Given that the research problem has 5 objective functions, it is not possible to plot the
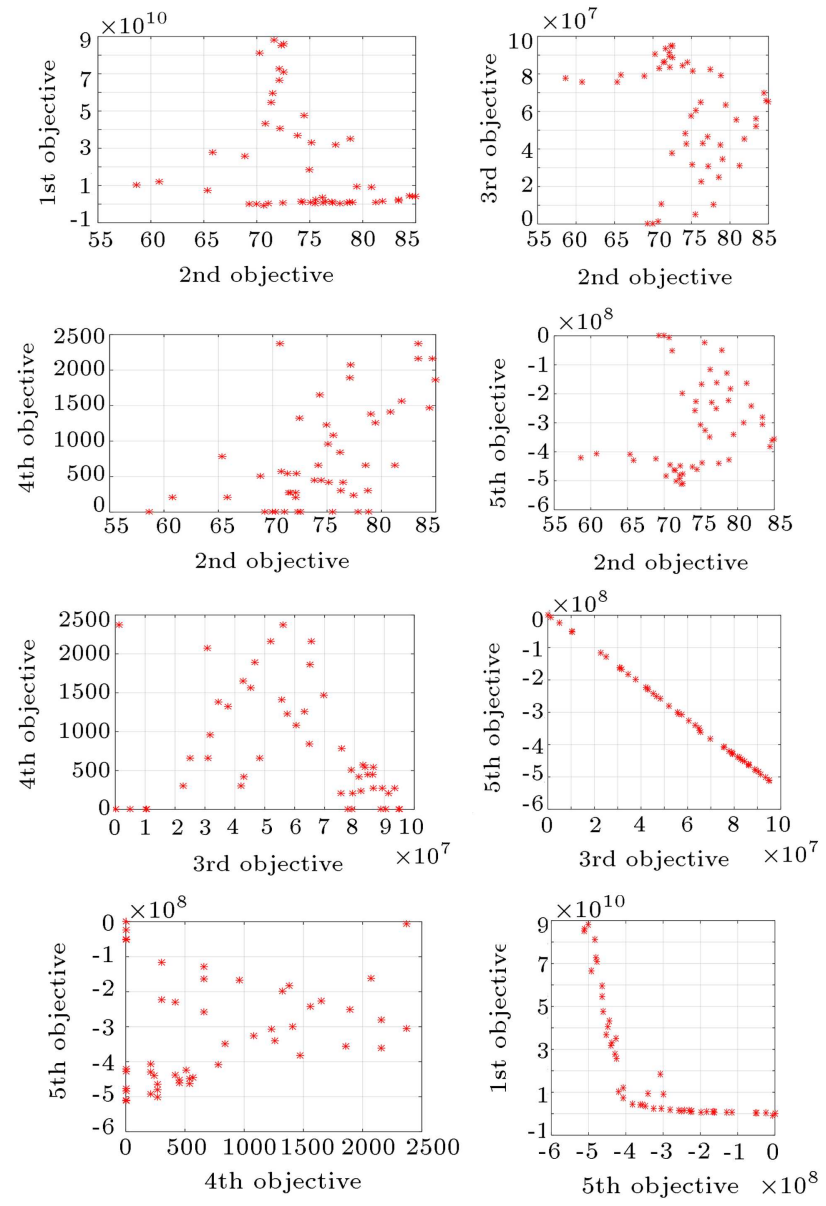

Figure 5. Comparison between objective functions, and examination of the level of quality and costs in relation to each other.

Pareto front in a 5-dimensional space since it cannot be imagined. Therefore, the results are plotted in pairs in a two-dimensional space (Figure 5 ). Figure 5 shows that:

- The first objective function had an exponential relationship with the third, fourth, and fifth objective function, and the increase of the first objective function increased the third objective function and decreased the fourth and fifth objective function. As the cost increased, the quality of the purchased goods improved, and the environmental impact and social responsibility were also reduced;

- The third objective function and the fifth objective function were linearly related and as the third objective function increased, the fifth objective function decreased. In other words, the improvement of the quality of purchased goods reduces the degree of environmental impact.

\section{Conclusion}

Supply chain design has always been one of the most 
important operational decisions of every organization since the availability of the proper supply system, in addition to reducing system costs, accelerates the delivery and receipt of goods, thereby improving the entire system. This effect becomes more prominent when the location selection problem can be examined with the organization's strategic problems simultaneously. Therefore, it seems desirable to choose both the location of the facilities and the supply chain at the same time. In supply chain problems, two factors deserve high attention: cost and agility or time to prepare orders. This becomes even more important when it comes to the supply chain of essentials. This situation in the business environment can cause a lot of uncertainty, which makes decision-making extremely difficult and risky. Thus, the development of intelligent systems and mathematical models in such environments is essential for the survival and maintenance of the market. In this paper, a mathematical model of the problem was proposed to develop the supply chain problem properly in terms of integrity and agility. To achieve the research purpose, a four-objective mathematical model with fuzzy parameters was first proposed. After defuzzification of the model, the PESA, NSGA-II, and SPEA-II algorithms were used to solve the model.

To solve the proposed model, the experimental sample problems were designed based on the SAIPA Company's collected data. The results obtained for the three proposed optimization algorithms were compared in terms of quality, dispersion uniformity, and runtime indices. The results indicated that the SPEA-II algorithm had a greater potential to explore and extract the possible responses and to achieve near-optimal solutions. Regarding uniformity and runtime indices, the PESA algorithm had better performance than the NSGA-II and SPEA-II algorithms. The solution time variations due to the increase in the size of the problem confirmed that the problem was NP-HARD.

The following recommendations are also put forth for future research:

- Designing a sustainable agile closed-loop supply chain using multi-objective optimization methods;

- Designing a sustainable agile retail supply chain using multi-objective optimization methods and expert systems;

- Designing a sustainable agile closed-loop supply chain using multi-objective optimization methods and expert systems.

\section{References}

1. Sharifi, H. and Zhengwen, Z. "A methodology for achieving agility in manufacturing organisations: An introduction", International Journal of Production Economics, 62(1-2), pp. 7-22 (1999).
2. Swafford, P.M., Ghosh, S., and Murthy, N. "The antecedents of supply chain agility of a firm: scale development and model testing", Journal of Operations Management, 24(2), pp. 170-188 (2006).

3. Ismail, H.S. and Sharifi, H. "A balanced approach to building agile supply chains", International Journal of Physical Distribution \& Logistics Management, 36(6), pp. 431-444 (2006).

4. Lin, C.T., Chiu, H., and Chu, P.Y. "Agility index in the supply chain", International Journal of Production Economics, 100(2), pp. 285-299 (2006).

5. Van Hoek, R.I., Harrison, A., and Christopher, M. "Measuring agile capabilities in the supply chain", International Journal of Operations \& Production Management, 21(1/2), pp. 126-148 (2001).

6. Van Hoek, R.I. "Epilogue-moving forward with agility", International Journal of Physical Distribution \& Logistics Management, 31(4), pp. 290-301 (2001).

7. Zain, M., Rose, R.Ch., Abdullah, I., and Masrom, M. "The relationship between information technology acceptance and organizational agility in Malaysia”, Information \& Management, 42, pp. 829-839 (2015).

8. Christopher, M. and Towill, D. "An integrated model for the design of agile supply chains", International Journal of Physical Distribution \& Logistics Management, 31(4), pp. 235-246 (2001).

9. Agarwal, A., Shankar, R., and Tiwari, M.K. "Modeling the metrics of lean, agile and leagile supply chain: An ANP-based approach", European Journal of Operational Research, 173(1), pp. 211-225 (2006).

10. Faisal, M.N., Banwet, D.K., and Shankar, R. "Quantification of risk mitigation environment of supply chains using graph theory and matrix methods", European Journal of Industrial Engineering, 1(1), pp. 22-39 (2007).

11. Gao, S., Wang, H., Xu, D., and Wang, Y. "An intelligent agent-assisted decision support system for family financial planning", Decision Support Systems, 44(1), pp. 60-78 (2007).

12. Swafford, P.M., Ghosh, S., and Murthy, N. "Achieving supply chain agility through IT integration and flexibility", International Journal of Production Economics, 116(2), pp. 288-297 (2008).

13. Mohd Beta, R.M.D. and Ali, K. "The influence of job burnout, perceived organizational support and islamic religiosity towards innovative work behavior among academics in Malaysian Research Universities, Klang Valley", Humanities \& Social Sciences Reviews, 5(2), pp. 71-81 (2017).

14. Gosling, J., Purvis, L., and Naim, M.M. "Supply chain flexibility as a determinant of supplier selection", International Journal of Production Economics, 128(1), pp. 11-21 (2010).

15. Ngai, E.W., Chau, D.C., and Chan, T.L.A. "Information technology, operational, and management competencies for supply chain agility: Findings from case studies", The Journal of Strategic Information Systems, 20(3), pp. 232-249 (2011). 
16. Moon, K.K.L., Yi, C.Y., and Ngai, E.W.T. "An instrument for measuring supply chain flexibility for the textile and clothing companies", European Journal of Operational Research, 222(2), pp. 191-203 (2012).

17. Yusuf, Y.Y., Musa, A., Dauda, M., El-Berishy, N., Kovvuri, D., and Abubakar, T. "A study of the diffusion of agility and cluster competitiveness in the oil and gas supply chains", International Journal of Production Economics, 147, pp. 498-513 (2014).

18. Gligor, D.M., Esmark, C.L., and Holcomb, M.C. "Performance outcomes of supply chain agility: when should you be agile?", Journal of Operations Management, 33, pp. 71-82 (2015).

19. Oliveira, O., Gamboa, D., and Fernandes, P. "An information system for the furniture industry to optimize the cutting process and the waste generated", Procedia Computer Science, 100, pp. 711-716 (2016).

20. Wu, K.J., Tseng, M.L., Chiu, A.S., and Lim, M.K. "Achieving competitive advantage through supply chain agility under uncertainty: A novel multi-criteria decision-making structure", International Journal of Production Economics, 190, pp. 96-107 (2017).

21. Chan, A.T., Ngai, E.W., and Moon, K.K. "The effects of strategic and manufacturing flexibilities and supply chain agility on firm performance in the fashion industry", European Journal of Operational Research, 259(2), pp. 486-499 (2017).

22. Han, J.H., Wang, Y., and Naim, M. "Reconceptualization of information technology flexibility for supply chain management: An empirical study", International Journal of Production Economics, 187, pp. 196215 (2017).

23. Goli, A., Ahmadi, S.A., Nasr Azadani, M., and Rezaei, H. "Providing a structured approach for evaluating and selecting suppliers in a supply chain", UCT Journal of Research in Science, Engineering and Technology, 1, pp. 17-31 (2017).

24. Battistella, C., De Toni, A.F., De Zan, G., and Pessot, E. "Cultivating business model agility through focused capabilities: A multiple case study", Journal of Business Research, 73, pp. 65-82 (2017).

25. Ocampo, J.R., Hernández-Matías, J.C., and Vizán, A. "A method for estimating the influence of advanced manufacturing tools on the manufacturing competitiveness of Maquiladoras in the apparel industry in Central America", Computers in Industry, 87, pp. 3151 (2017).

26. Cruz, J.M. "Modeling the relationship of globalized supply chains and corporate social responsibility", Journal of Cleaner Production, 56, pp. 73-85 (2013).

27. Hsueh, C.F. "A bilevel programming model for corporate social responsibility collaboration in sustainable supply chain management", Transportation Research Part E: Logistics and Transportation Review, 73, pp. 84-95 (2015).
28. Elandaloussi, Z., Benbba, B., and Ameziane, H. "The impact of SCRM strategies on supply chain resilience: A quantitative study in the Moroccan manufacturing industry", International Journal of Supply Chain management, 6(4), pp. 70-76 (2017).

29. Montazeri-Gh, M. and Mahmoodi-K, M. “An optimal energy management development for various configuration of plug-in and hybrid electric vehicle", Journal of Central South University, 22(5), pp. 1737-1747 (2015).

30. Corne, D.W., Jerram, N.R., Knowles, J.D., and Oates, M.J. "PESA-II: Region-based selection in evolutionary multi objective optimization", In Proceedings of the 3rd Annual Conference on Genetic and Evolutionary Computation, Morgan Kaufmann Publishers Inc, pp. 283-290 (July, 2001).

31. Jiménez, M., Arenas, M., Bilbao, A., and Rodres, M.V. "Linear programming with fuzzy parameters: an interactive method resolution", European Journal of Operational Research, 177(3), pp. 1599-1609 (2007).

32. Tavakkoli-Moghaddam, R., Azarkish, M., and Sadeghnejad-Barkousaraie, A. "A new hybrid multiobjective Pareto archive PSO algorithm for a biobjective job shop scheduling problem", Expert Systems with Applications, 38(9), pp. 10812-10821 (2011).

33. Deb, K. "A Fast and elitist multiobjective genetic algorithm: NSGA-II", IEEE Transactions on Evolutionary Computation, 6, pp. 182-198 (2002).

34. Zitzler, E., Laumanns, M., and Thiele, L. "SPEA2: Improving the strength Pareto evolutionary algorithm", Proceedings of the Evolutionary Methods for Design, Barcelona, Spain (2000)

\section{Biographies}

Ebrahim Azizi is a $\mathrm{PhD}$ candidate in the Industrial Engineering Department of Islamic Azad University South Tehran, Tehran, Iran. He received BS and MS degrees in Industrial Engineering from Islamic Azad University, Parand, Iran in 2012 and 2013, respectively. His research interests include supply chain management and decision support system.

Hassan Javanshir is an Assistant Professor of Industrial Engineering in the Department of Industrial Engineering, Islamic Azad University, South Tehran, Tehran, Iran. He received BS and MS degrees in Industrial Engineering from Amirkabir University of Technology, Tehran, Iran, in 1987 and 1991, respectively, and $\mathrm{PhD}$ degree in the same field from University of Science and Research Branch, Islamic Azad University, Tehran, Iran in 2005. His research interests include mathematical programming and reliability.

Davood Jafari is an Associate Professor in the Department of Industrial Engineering, Faculty of Engineering, Islamic Azad University, Tehran, Parand, 
Iran. He received BS degree in Industrial Engineering Production and MS degree in Industrial Engineering from Amirkabir University of Science \& Technology, Tehran, Iran, in 1998 and 2000, respectively, and PhD degree in the same field from Amirkabir University of Technology Tehran, Iran in 2002. His research interests include production and inventory, SCM, location and facility planning, VRP, modeling and optimization problem, system engineering.

Sadoullah Ebrahimnejad is an Associate Professor at the Department of Industrial Engineering, Karaj Branch, Islamic Azad University, Karaj, Iran. He received BS and MS degrees in Industrial Engineering from Iran University of Science \& Technology and Amirkabir University of Technology, Tehran, Iran in 1986 and 1993, respectively, and $\mathrm{PhD}$ degree in the same field from Islamic Azad University, Science and Research Branch, Tehran, Iran, 2001. His research interests include operations research, risk management, supply chain management, operation management, and fuzzy MADM. 